\author{
Associate Professor Cezar-Petre SIMION, PhD \\ Email: cezar.simion@man.ase.ro \\ The Bucharest University of Economic Studies \\ Associate Professor Irinel MARIN, PhD \\ Email: irinel.marin@ase.ro \\ The Bucharest University of Economic Studies
}

\title{
PROJECT COST ESTIMATE AT COMPLETION: EARNED VALUE MANAGEMENT VERSUS EARNED SCHEDULE-BASED \\ REGRESSION MODELS. A COMPARATIVE ANALYSIS OF THE MODELS APPLICATION IN THE CONSTRUCTION PROJECTS IN ROMANIA
}

Abstract. This paper explores the application of CEAC (Cost Estimate at Completion) calculation models for construction projects in Romania. Four models based on Earned Value Management, a GGM (Gompertz Growth) based model, and an Earned Schedule GGM based model were selected. Based on the data analyzed for 30 projects, the percentage error was determined to apply the four EVM models and the two GGMs based on each project. Percentage error for applying ES GGM based models was lower than for EVM models (Cost Performance Index, Composite Index, Critical Ratio, Moving Average). The accuracy and precision of ES-GGM based models have proven superior in all project life cycles compared to EVM models.

Keywords: project, cost, earnedvalue, management, schedule, models.

JEL Classification: M19, M29, C13, L74

\section{Introduction}

Completing projects on time and meeting initial cost estimates are the most important issues in building construction management. However, in Romania, the construction sector, especially in the public domain, offers countless examples of delayed construction projects or the cost overtaken by the initial estimates. In the case of construction projects, the consequences of delays or cost overruns are difficult to bear for any of the partners involved. For construction companies, they impose late payment penalties or a reduction in the share of the profit obtained from the project, and for the beneficiary they mean losing market opportunities and potential revenues. In the case of private firms, especially when project financing is not made from its own sources, delays in execution and estimated cost overruns may result in insolvency or even bankruptcy due to inconsistency between the 
completion of projects and the commencement of reimbursement obligations to financiers.

The cost management of construction projects comprises four essential phases: resource planning, cost estimation, cost budgeting and cost control. The initial estimate of the cost, most often imperfect, involves calculating the costs generated by the use of the resources planned for the implementation of the projects. There are often significant differences between the initial cost estimates and real costs of construction projects due to: the inappropriate use of estimates, the difficulty in estimating costs for unique activities that have not occurred in earlier projects, the use of irrelevant data and the use of outside estimates context.

In the field of construction, the correlation between the cost of physical progress of project work and the financial progress of projects is essential. In the past decades, Earned Value Management techniques have been most used to correlate project cost progress and physical progress. Another possibility for improving project cost estimate at completion are Earned Schedule-based regression models. These are less applied in the field of construction because they are less well known and harder to understand by project managers.

Therefore, it is necessary to study from the point of view of the accuracy of the results obtained which is the model through which the best results for the project cost are estimated at completion.

\section{Literature review}

For nearly 40 years, Earned Value Management (EVM) was the most commonly used estimation methodology for predicting the cost of construction projects. This methodology integrates the time and cost of the project into the same measurement system. EVM requires a permanent comparison of the budgeted cost of the scheduled workload (which represents the cumulative budget showing the cost progress in line with the initial planning of the project), the actual cost of the work performed and the budgeted cost of the work performed (value earned). EVM has been so widely applicable because it is based on the data available from the project progress reports.

In EVM, the CEAC (Cost Estimate at Completion), must be determined as the sum of two elements: the actual cost of the work performed at the actual time and the estimated cost of the remaining work.

Lipke (2004) classified the techniques used for CEAC calculation in indexbased or regression-based techniques. Index-Based methods have a number of limitations because they rely on past information. Fleming and Koppelman (2006) but also Kim and Reinschmidt (2011) considered that the main issue of Cost Estimate at Completion using index-based techniques is that the remaining budget is adjusted using a performance index.

The main performance indices used in applying EVM are according to PMI (2011): cost performance index, critical ratio, composite index and moving

DOI: 10.24818/18423264/52.3.18.14 
Project Cost Estimate at Completion: Earned Value Management versus Earned Schedule-based Regression Models. A Comparative Analysis of the Models Application in the Construction Projects in Romania

average. The cost performance index starts from the assumption that the future cost performance of construction projects will be the same as in the past (from project start to calculation). Compared to the cost performance index, the critical ratio is further influenced by past schedule performance. The composite index is influenced, but not by the cost and program performance. The same feature is present in the moving average.

Fleming and Koppelman (2006) considered that the calculation of CEAC in the early stages of the project life cycle is affected by the fact that the available data on the project's past are not very numerous. As project progress progresses, the magnitude of past data increases and, implicitly, the accuracy of estimates made in the phases closest to the completion of the project.Simion-Melinte(2016) found "a positive correlation between the types of cost estimates and the accuracy of the estimates".

Taking into account index-based techniques, regression-based techniques have been developed in which regression model parameters describe the evolution of project cost over its life cycle. The Earned Schedule (ES) technique removes the limitations inherent to the EVM methodology by calculating Expected Duration at Completion (EDAC) of a project (Lipke, 2003). Several comparative studies between EVM and the Earned Schedule have been conducted and have shown that ES provide greater accuracy of estimates compared to Schedule Performance Index methodologies (Vandevoorde and Vanhoucke, 2006).

In the literature, two criteria were developed to assess the cost of projects: accuracy and precision. Not all specialists consider that the two criteria are of equal importance in predictive models, most of them considering that accuracy is the most important and most used criterion (Yokum and Armstrong, 1995). To measure the CEAC accuracy, the percentage error and the mean absolute percentage error are used and the standard deviation can be used for precision.

Narbaev and De Marco (2014) conducted a comparative study on the improvement of the CEAC calculation formula by integrating four growth models (Bass, Gompertz, Logistic and Weibull). The conclusion of the study by Narbaev and De Marco was that the Gompertz Growth Model (GGM) is the "best statistically valid model converging to approximate values of its parameters in nonlinear regression curve fitting." The GGM generic function is:

$$
G G M(x)=\alpha e^{\left[-e^{(\beta-\gamma x)}\right]}
$$

$\alpha$ - future value asymptote of the model that represents the final cost (which is never attained) as time (x) tends to infinity;

$\beta$ - intercept indicating an initial budget size;

$\gamma$ - a scale parameter that governs the cost growth rate $(\mathrm{GR}=\alpha \gamma / \mathrm{e})$.

In the Gompertz function the value of parameter $\alpha$ represents the horizontal asymptote of the graph. First order derivative is: 


$$
\mathrm{g}^{\prime}(\mathrm{x})=\alpha \gamma e^{-e^{\beta-x \gamma}+\beta-x \gamma}
$$

Second-order derivative is:

$$
\mathrm{g}^{\prime \prime}(\mathrm{x})=\alpha \gamma\left(-\gamma+e^{\beta-x \gamma} \gamma\right) e^{-e^{\beta-x \gamma}+\beta-x \gamma}
$$

The inflection point is equal to $\beta$ / $\mathrm{c}$ with the solution of the equation $\mathrm{g} "(\mathrm{x})=0$. The following figure shows the graph of the Gompertz function for $\alpha=10, \beta=2, \gamma=$ 1.

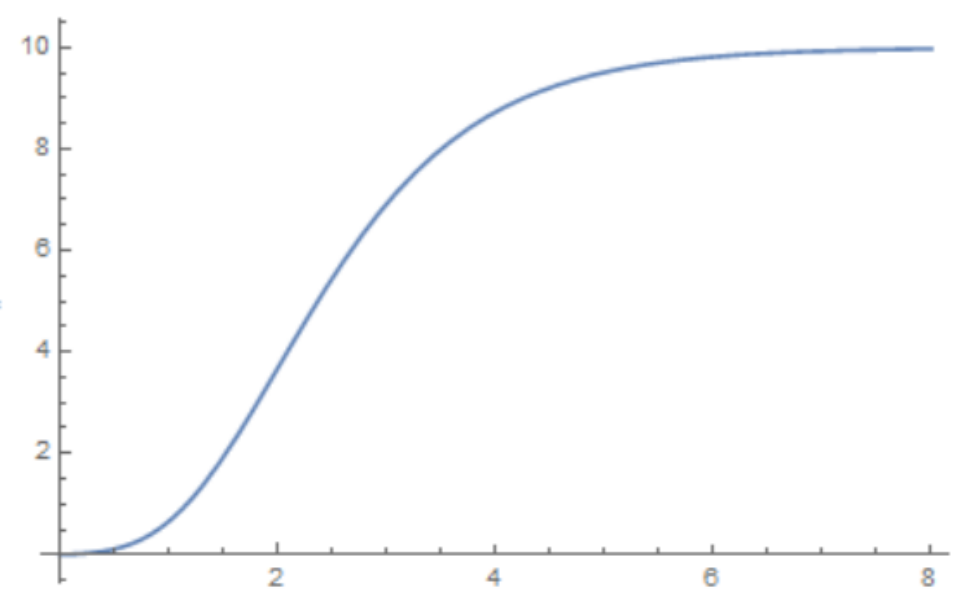

Figure 1. The graph of the Gompertz function for $\alpha=10, \beta=2, \gamma=1$

GGM integration in the CEAC formula has proven to be the most accurate compared to other growth models (Bass, Gompertz, Logistic). Also in 2014, Narbaev and De Marco have proposed a calculation equation of CEAC that integrates GGM into the Earned Schedule technique equation. The equation proposed by Narbaev and De Marco for CEAC calculation is a combination of index-based and regression models. In the study by Narbaev and De Marco, the model that integrates GGM into the Earned Schedule technique equation has proven to be the most appropriate from the point of view of accuracy, precision and influence of progress on CEAC. The second study by Narbaev and Marco was carried out on a relatively small sample of projects.

\section{Research methodology}

Since no comparative analysis of EVM and Earned Schedule-GGM implementation in the project cost forecast has been carried out in the literature, for this research the following objectives have been set:

- applying the EVM models for the CEAC calculation on a representative number of construction projects in Romania and measuring their accuracy and accuracy;

DOI: $10.24818 / 18423264 / 52.3 .18 .14$ 
Project Cost Estimate at Completion: Earned Value Management versus Earned Schedule-based Regression Models. A Comparative Analysis of the Models Application in the Construction Projects in Romania

- application of GGM-based and Earned Schedule-based regression models (ES-GCM) for the calculation of CEAC on a representative number of construction projects in Romania and measurement of their accuracy and precision;

- comparative analysis of the results obtained.

Taking into account the previously formulated objectives, has been developed a research methodology that includes the following stages:

1. Forming a sample of representative (typological) projects for the Romanian construction sector on which the EVM models, GGM-based and Earned Schedule-based regression models (ES-GCM) for CEAC calculation will be applied. Selection criteria were used: the number of construction projects in Romania (by NACE code) and the value of construction projects (by NACE code) according to INS data. Requests for access to project documentation, contracting and project progress reports were sent to 150 construction projects from the 8 development regions. 110 Project Managers responded to the requests and provided complete documentation only to the teams of 30 construction projects. However, the number of projects analyzed is high compared to previous studies in this area.

2. Selection of data from design, contracting and progress reports and their preparation for EVM model calculations, GGM and Earned Schedule-based regression models (ES-GCM).

3. Apply EVM specific equations for CEAC calculation for each project:

$$
C E A C(x)=A C(x)+(B A C-E V(x)) / P I(x)
$$

where:

$\operatorname{CEAC}(x)$ - Cost Estimate at Completionat actual time (time $\mathrm{x})$;

$A C(x)$ - Actual Cost of performed work at actual time (time $\mathrm{x}$ );

$B A C$ - Budget at Completion;

$E V(x)-E$ arned Value (EV) at actual time (time $\mathrm{x})$;

$P I(x)$ - Performance Index at actual time (time $\mathrm{x}$ ).

The Performance Index calculation was performed for all types of performance indices used in EVM (PMI, 2011):

- Cost Performance Index : CPI = EV/AC;

- Critical ratio: $\mathrm{CR}=\mathrm{CPI} \times \mathrm{SPI}$;

- Composite index: $\mathrm{CI}=0,8 \mathrm{CPI} \times 0,2 \mathrm{SPI}$;

- Moving average (MA):

$$
M A=\sum_{i=1}^{n=3} E V / \sum_{i=1}^{n=3} A C
$$


4. Application of the GGM-based specific equations (Narbaev-De Marco, 2014) for the CEAC calculation for each project:

$$
\operatorname{CEAC}(x)=A C(x)+[G G M(1.00)-G G M(x)] B A C
$$

where:

GGM(1.00) - the result of GGM function when time(x) is 1 (project is complete).

$\operatorname{GGM}(x)$ - the result of the GGM function when time (x) is at actual time.

5. Application of specific Earned Schedule-based regression models (ESGCM, Narbaev-De Marco, 2014) for CEAC calculation for each project:

$$
\begin{gathered}
C E A C(x)=A C(x)+[G G M(C F(x))-G G M(x)] B A C \\
C F(x)=E D A C(x) / P D
\end{gathered}
$$

$C F(x)$ - completion factor when time (x) is at actual time;

$\operatorname{EDAC}(x)$ - Expected Duration at Completion when time (x) is at actual time PD- Planned Duration.

6. Analyzing the accuracy of the results of the three methods using percentage error (PE) and mean absolute percentage error (MAPE):

$$
\begin{gathered}
P E \%=\frac{\text { CEAC }- \text { CatC }}{\text { CatC }} 100 \% \\
M A P E \%=\frac{100 \%}{n} \sum_{i=1}^{n} \frac{\mid C E A C i-\text { CatC } i \mid}{\text { CatC } i}=\frac{1}{n} \sum_{i=1}^{n}|P E i| \%
\end{gathered}
$$

where :

CatC - cost at completion

$\mathrm{n}$ - number of projects

7. Analysis of the precision of the results of the three methods using the standard deviation $(\mathrm{SD} \%)$ :

$$
S D \%=\sqrt{\frac{\sum_{i=1}^{n}(P E i-M P E)^{2}}{n} \%}
$$

where MPE - mean percentage error

8. Comparative analysis of the results obtained in stages 6 and 7 and formulation of research findings on the application of EVM, GGMbased and Earned Schedule-based regression models (ESC-GCM) for CEAC calculation.

\section{Research results}

The results of the research are related to the PE measurement for all CEAC calculation models for each of the analyzed projects, the analysis of the accuracy of

DOI: $10.24818 / 18423264 / 52.3 .18 .14$ 
Project Cost Estimate at Completion: Earned Value Management versus Earned Schedule-based Regression Models. A Comparative Analysis of the Models Application in the Construction Projects in Romania

the results by the mean absolute percentage error and the precision analysis of the results using the standard deviation (for each stage of the life cycle).

The main features of the projects analyzed, taken from the initial studies and documentation, and the project progress reports are presented in the following table.

Table 1

The main elements of the projects analyzed

\begin{tabular}{|c|l|c|c|c|}
\hline $\begin{array}{c}\text { Project } \\
\text { number }\end{array}$ & \multicolumn{1}{c|}{ Project type } & BAC & $\begin{array}{c}\text { Duration } \\
\text { (months) }\end{array}$ & $\begin{array}{c}\text { Progress } \\
\text { reporting } \\
\text { period }\end{array}$ \\
\hline 1 & Residential buildings & 8420000 & 18 & $2016-2017$ \\
\hline 2 & Non-residential buildings & 7550000 & 24 & $2016-2017$ \\
\hline 3 & Construction of roads & 24215000 & 18 & $2016-2017$ \\
\hline 4 & Construction of railways & 36560200 & 32 & $2016-2017$ \\
\hline 5 & Construction of bridges & 8450543 & 24 & $2016-2017$ \\
\hline 6 & Building finishing & 871155 & 12 & 2016 \\
\hline 7 & Tunnels & 14500160 & 24 & $2016-2017$ \\
\hline 8 & Water project & 18800000 & 24 & $2016-2017$ \\
\hline 9 & Utility project & 1235350 & 36 & $2016-2017$ \\
\hline 10 & Demolition & 9200441 & 36 & 2016 \\
\hline 11 & Construction of bridges & 3210900 & 12 & $2016-2017$ \\
\hline & Electrical, plumbing and other & 2400804 & 12 & 2016 \\
\hline 12 & construction installation activities & 3501500 & 18 & $2016-2017$ \\
\hline 13 & Building finishing & 4104000 & 18 & $2016-2017$ \\
\hline 14 & Residential buildings & 4250050 & 24 & $2016-2017$ \\
\hline 15 & Residential buildings & 633100 & 6 & 2016 \\
\hline 16 & Construction of roads & 4115238 & 12 & 2016 \\
\hline 17 & Site preparation & 500120 & 6 & 2017 \\
\hline 18 & Residential buildings & 504813 & 6 & 2017 \\
\hline 19 & Site preparation & 1511120 & 12 & 2016 \\
\hline 20 & Site preparation & 8215323 & 24 & $2016-2017$ \\
\hline 21 & Demolition & 1100442 & 12 & 2016 \\
\hline 22 & Construction of bridges & 12735120 & 24 & $2016-2017$ \\
\hline 23 & Demolition & 8710214 & 24 & $2016-2017$ \\
\hline 24 & Construction of roads & 7333254 & 24 & $2016-2017$ \\
\hline 25 & Construction of roads & 8251440 & 18 & $2016-2017$ \\
\hline 26 & Non-residential buildings & 44126000 & 12 & 2016 \\
\hline 27 & Non-residential buildings & 351200 & 24 & $2016-2017$ \\
\hline 28 & Residential buildings & & & $2016-2017$ \\
\hline 29 & Construction of roads & & \\
\hline 30 & Residential buildings & & & \\
\hline & & & & \\
\hline
\end{tabular}


Cezar-Petre Simion, Irinel Marin

For the PE calculation, we consider the results obtained for the CEAC calculation at the end of the design phase relevant as the project is still in its infancy, the data on its implementation are sufficient to achieve estimates but insignificant in relation to the project budget and the accuracy of the estimation models can be tested suitable. The results for PE calculation for all CEAC calculation models for each of the projects analyzed are presented in the following table (table 2).

Table 2

CEAC accuracy results for the design stage (in PE, \%)

\begin{tabular}{crrrrrr}
\hline Project number & GGM -based & ES-GGM based & \multicolumn{1}{c}{ CPI } & \multicolumn{1}{c}{ CR } & \multicolumn{1}{c}{ Cl } & \multicolumn{1}{c}{ MA } \\
\hline 1 & 2.24 & 1.41 & 7.23 & 6.25 & 8.46 & 8.01 \\
2 & 5.75 & 3.25 & 8.21 & 6.45 & 8.88 & 8.47 \\
3 & 3.11 & 4.11 & 6.25 & 16.21 & 7.21 & 8.32 \\
4 & 3.89 & 1.45 & 6.44 & 11.25 & 12.11 & 6.11 \\
5 & 2.45 & -0.89 & 12.15 & 18.15 & 15.23 & 12.02 \\
6 & -4.3 & -1.44 & -7.24 & -11.23 & -8.36 & -8.89 \\
7 & -5.21 & 3.23 & 7.23 & -4.23 & 11.06 & 8.41 \\
8 & 7.47 & 2.89 & 11.84 & -11.15 & 11.94 & 12.32 \\
9 & 7.44 & 5.11 & 9.25 & 17.21 & 11.23 & 11.12 \\
10 & 8.23 & 4.89 & 14.55 & 11.45 & 14.44 & 12.23 \\
11 & 8.41 & 6.25 & 12.23 & 4.43 & 8.66 & 24.15 \\
12 & 2.23 & 1.87 & 4.75 & 6.21 & 6.23 & 7.21 \\
13 & -3.25 & 1.25 & 6.25 & 32.18 & 8.51 & 6.45 \\
14 & -1.69 & -1.23 & -7.65 & -11.25 & 16.24 & -11.12 \\
15 & 4.51 & 2.56 & -12.23 & -18.02 & -15.11 & -15.24 \\
16 & 5.28 & 2.82 & 11.25 & 17.23 & 18.25 & 11.38 \\
17 & 6.11 & 4.13 & 12.23 & 17.89 & 11.99 & 14.45 \\
18 & -3.23 & -1.12 & -4.72 & -8.52 & -5.89 & -5.57 \\
19 & -6.17 & -2.23 & -8.18 & -15.55 & -12.07 & -9.01 \\
20 & 4.07 & 3.32 & -4.07 & 4.87 & -7.34 & -4.15 \\
21 & -8.8 & -2.11 & -21.12 & -28.25 & -19.05 & -25.02 \\
22 & 3.89 & 3.45 & 4.42 & 6.96 & 4.82 & 4.45 \\
23 & 5.58 & 4.58 & 8.21 & 6.23 & 9.65 & 8.98 \\
24 & 4.14 & 3.81 & 7.4 & 17.31 & 4.18 & 8.25 \\
25 & 6.37 & 4.36 & 11.02 & 10.89 & 23.16 & 16.04 \\
26 & -2.08 & -1.15 & -6.07 & 5.07 & -7.58 & -6.82 \\
27 & 2.15 & 2.02 & 4.23 & 6.18 & -8.11 & 4.44 \\
28 & 7.31 & 5.41 & 16.18 & 22.57 & 18.83 & 16.23 \\
29 & -3.04 & -2.15 & -8.01 & -13.24 & 9.74 & 9.01 \\
30 & 4.02 & 3.86 & 7.12 & 16.04 & 9.6 & 8.25 \\
\hline & & & & & &
\end{tabular}

All calculation models have both positive and negative PE values. For all projects, EVM computing models show higher PE values than ES-GGM based

DOI: 10.24818/18423264/52.3.18.14 
Project Cost Estimate at Completion: Earned Value Management versus Earned Schedule-based Regression Models. A Comparative Analysis of the Models Application in the Construction Projects in Romania

computing models. Application of ES-GGM based calculation models for CEAC determination shows lower PE values in 29 of 30 projects compared to GGM based calculation models.

The determination of the CEAC accuracy for the EVM and ES-GGM based calculation models was performed for all phases of conception and implementation in the life cycle of a construction project (feasibility, design, planning, execution, reception) using mean absolute percentage error (table 3 ).

Table 3

CEAC Accuracy (MAPE \%)

\begin{tabular}{lcccrrr}
\hline $\begin{array}{l}\text { Completion } \\
\text { stage }\end{array}$ & $\begin{array}{c}\text { GGM - } \\
\text { based }\end{array}$ & $\begin{array}{c}\text { ES-GGM } \\
\text { based }\end{array}$ & CPI & CR & \multicolumn{1}{c}{ CI } & \multicolumn{1}{c}{ MA } \\
\hline Feasibility & 5.24 & 3.81 & 9.45 & 12.89 & 11.06 & 10.88 \\
Design & 4.75 & 2.95 & 8.92 & 12.75 & 10.57 & 10.40 \\
Planning & 4.55 & 2.85 & 8.08 & 9.16 & 8.73 & 8.41 \\
Execution & 4.23 & 2.04 & 5.77 & 7.04 & 6.35 & 6.17 \\
Reception & 3.89 & 1.17 & 4.56 & 5.81 & 4.92 & 5.12 \\
\hline
\end{tabular}

The CEAC accuracy (MAPE\%) due to the use of ES - GGM based models is superior to all phases of the life cycle of the construction projects analyzed compared to the application of Earned Value Management index - based calculation models. In project design phases (feasibility, design, planning), the accuracy of ES-GGM based calculation models is much higher than EVM models. As the approach to the end of the projects (proximity to the reception phase) increases the accuracy of index-based models that are specific to Earned Value Management, but the utility of their application at these times is obviously lower.

Thus, while MAPE for ES-GGM based models is 3.81 in the feasibility phase and 1.17 at the lowest MAPE reception stage of the EVM (Cost Performance Index) specific models is 9.45 in the feasibility phase and 4.56 in the project execution phase.

The CEAC precision for the 30 projects analyzed was performed for both ES-based and EVM-based models by SD calculation for each major phase of the life cycle of the projects (Table 4).

\section{Table 4}

\begin{tabular}{lcccrrr}
\hline $\begin{array}{c}\text { Completion } \\
\text { stage }\end{array}$ & $\begin{array}{c}\text { GGM - } \\
\text { based }\end{array}$ & $\begin{array}{c}\text { ES-GGM } \\
\text { based }\end{array}$ & CPI & \multicolumn{1}{c}{ CR } & CI & \multicolumn{1}{c}{ MA } \\
\hline Feasibility & 5.11 & 3.51 & 9.25 & 13.11 & 10.81 & 10.72 \\
Design & 4.67 & 2.50 & 9.01 & 13.73 & 10.66 & 10.58 \\
Planning & 4.44 & 2.35 & 7.84 & 9.85 & 8.23 & 8.27 \\
Execution & 4.12 & 1.99 & 5.21 & 7.83 & 6.14 & 5.65 \\
Reception & 3.65 & 1.09 & 4.73 & 5.95 & 4.84 & 5.24 \\
\hline
\end{tabular}


In terms of CEAC precision, ES -GGM based models are superior to EVM models in all phases of the life cycle of construction projects. Although the precision of all models (GGM-based, ES-GGM based, EVM) increases as project closure approaches, ES-GGM based models have proven to be three times more precise in the feasibility phase compared to EVM models. This gap between ESGGM based and EVM models is maintained in the execution phase.

\section{Conclusions}

In this paper a research has been carried out on the application of CEAC estimation models for construction projects. For this CEAC estimation was applied: an ES-GGM based model, a GGM based model, and four performancespecific EVM models. For the 30 projects analyzed, the PE was determined in the case of each model. PE was much lower in all ES-GGM based models than in EVM models (CPI, CI, CR, MA).

To determine the CEAC accuracy MAPE has been calculated for each phase of the life cycle of the projects. In the initial stages of project implementation, CEAC accuracy is much higher than CEAC determination by applying EVM (CPI, CI, CR, MA) models by applying ES-GGM based models. The accuracy of EVM models increases as projects progress but the utility of their application is no longer the same. Although the gap between MAPE for ES GGM based models and MAPE for EVM models is reduced in the final stages it remains a significant one.

CEAC precision is higher for ES GGM based models compared to EVM models in all project phases. ES GGM based models are three times more precise in the feasibility phase compared to EVM models. The same precision difference between the two types of models is also maintained in the execution phase.

The application of ES GGM based models to CEAC for construction projects is still limited by several factors: the high difficulty of applying the mathematical model in comparison with EVM models; spreading EVM models compared to ES based; time to analyze the data. For these reasons, project managers adopt and apply index-based EVM models more easily, although this study reveals superior accuracy and precision in the application of ES GGM based models.

The application of ES GGM based models for CEAC should not be limited to the project implementation period. In future research, we propose to apply ES GGM based models for Life Cycle Cost (LCA) calculation, extending the scope of the method to the construction project exploitation period.

DOI: $10.24818 / 18423264 / 52.3 .18 .14$ 
Project Cost Estimate at Completion: Earned Value Management versus Earned Schedule-based Regression Models. A Comparative Analysis of the Models Application in the Construction Projects in Romania

\section{REFERENCES}

[1]Ahiaga-Dagbui, D. D., Love, P. E. D., Smith, S., Ackermann, F. (2017), Toward a Systemic View to Cost Overrun Causation in Infrastructure Projects: A Review and Implications for Research. Project Management Journal, 48(2), 88-98;

[2]Cantarelli, C., Flyvbjerg, B., Molin, E. J. \& van Wee, B. (2010), Cost Overruns in Large-Scale Transportation Infrastructure Projects: Explanations and their Theoretical Embeddedness. European Journal of Transport Infrastructure Research, 10(1), 5-18;

[3]De Marco, A., Rosso, M., Narbaev, T. (2016b), Nonlinear Cost Estimates at Completion Adjusted with Risk Contingency. Journal of Modern Project Management, 4(2), 24-33;

[4]Fleming, Q.W., Koppelman, J.M. (2006), Earned Value Project Management, third ed. Project Management Institute, Inc., Newtown Square, PA; [5]Ishii, N., Takano, Y. \& Muraki, M. (2014), An Order Acceptance Strategy under Limited Engineering Man-hours for Cost Estimation in EngineeringProcurement-Construction Projects ;International Journal of Project Management 32, 519-528;

[6]Jørgensen, M., Halkjelsvik, T. \&Kitchenham, B.(2012), How Does Project Size Affect Cost Estimation Error? Statistical Artifacts and Methodological Challenges ; International Journal of Project Management 30, 839-849;

[7] Kim, B.C., Reinschmidt, K.F. (2011), Combination of Project Cost Forecasts in Earned Value Management. Journal of Construction Engineering and Management 137 (11), 958-966;

[8] Lipke, W. (2004), Independent Estimates at Completion: Another Method. Crosstalk. J. Def. Softw. Eng. 26-30 (October);

[9]Lipke, W. (2003), Schedule is Different . The Measurable News. 31-34

(Summer);

[10]Love, P. E. D., Smith, J., Simpson, I., Regan, M. \&Olatunji,O.(2015),

Understanding the Landscape of Overruns in Transport Infrastructure

Projects. Environment and Planning B: Planning and Design, 42(3);

[11]Narbaev, T., De Marco, A. (2014), Combination of Growth Model and

Earned Schedule to Forecast Project Cost at Completion. Journal of Construction Engineering and Management. 140 (1);

[12]Narbaev, T., De Marco, A. (2014), An Earned Schedule Based Regression

Model to Improve Cost Estimate at Completion. International Journal of Project Management., 32(6), 1007-1018;

[13]PMI (2011), Practice Standard for Earned Value Management, second ed.

Project Management Institute, Inc., Newtown Square, PA; 
[14]Seber, G.A., Wild, C.J. (1989), Nonlinear Regression. John Wiley \& Sons; New York, NY;

[15]Simion-Melinte C.(2016), Factors Influencing the Choice of Cost Estimates Types and the Accuracy of Estimates for Construction Projects. Proceedings of the $10^{\text {th }}$ International Management Conference, "Challenges of Modern Management", November 3rd-4th,2016, 50-56;

[16]Vandevoorde, S., Vanhoucke, M. (2006), A Comparison of Different Project Duration Forecasting Methods Using Earned Value Metrics. International Journal of Project Management, 24 (4), 289-302;

[17]Yokum, J.T., Armstrong, J.S. (1995), Beyond Accuracy: Comparison of Criteria Used to Select Forecasting Methods .Int. J. Forecast. 11 (4), 591-597.

DOI: $10.24818 / 18423264 / 52.3 .18 .14$ 